\title{
Study of toxoplasmosis and toxocariasis in patients suffering from ophthalmic disorders using serological and molecular methods
}

\author{
Jasem Saki $\mathbb{D} \cdot$ Elham Eskandari $\cdot$ Mostafa Feghhi
}

Received: 13 October 2019/Accepted: 18 April 2020/Published online: 18 May 2020

(C) The Author(s) 2020

\begin{abstract}
Introduction Toxoplasma gondii is an intracellular protozoan parasite that can cause ocular toxoplasmosis with most complications such as retinal detachment. Toxocara parasite, round worm, found in dogs and cats appears as larva migrans in humans can cause serious ocular complications such as debilitating vision loss.In Khuzestan province, southwest of Iran, T. gondii infection has been reported to be significant but toxocariasis was rare. However, the frequency of ocular toxoplasmosis and toxocariasis has not been studied in this area. The aim of this study was to evaluate the ocular toxoplasmosis and ocular toxocariasis using serological and molecular methods.

Method In this case control study, 310 patients were identified by ophthalmologist as ocular toxoplasmosis
\end{abstract}

\section{J. Saki}

Infectious and Tropical Diseases Research Center, Health Research Institute, Ahvaz Jundishapur University of

Medical Sciences, Ahvaz, Iran

e-mail: Jasem.saki@gmail.com

E. Eskandari

Department of Medical Parasitology, Faculty of Medicine, Ahvaz Jundishapur University of Medical Sciences, Ahvaz, Iran

\section{Feghhi ( ()}

Department of Ophthalmology, Imam Khomeini Hospital, Ahvaz Jundishapur University of Medical Sciences,

Ahvaz, Iran

e-mail: mfeghhi@ajums.ac.ir and then $5 \mathrm{cc}$ of venous blood samples were taken from each of them. Serum samples and buffy coat were prepared and ELISA was used to detect IgG and IgM anti-Toxoplasma antibodies and the molecular PCR was used to detect Toxoplasma DNA parasite in buffy coats. ELISA test was used to detect of IgG antiToxocara antibodies.

Results Totally, for ocular toxoplasmosis, 130 $(41.93 \%)$ of 310 patients were positive by ELISA, of them $121(39 \%)$ IgG positive and nine (2.9\%) IgM positive were diagnosed. Of 121 cases with $\mathrm{IgG}^{+}, 119$ (98.35\%) were diagnosed with high IgG avidity indicating chronic phase of the infection. For ocular toxocariasis evaluation, antibodies against Toxocara were not detected in any of the samples. By PCR molecular method, 11 out of 310 patients $(3.54 \%)$ had T. gondii DNA in the blood. In control, in total, 21 cases were detected positive by serology method, which showed a significant difference with the results of the case group $(P<0.05)$.By PCR method, only three cases showed positive which also indicated significant difference with result of case group (3 vs 9) $(P<0.05)$. In the control group, also no anti-toxocara antibodies were found.

Conclusion It can be concluded that $T$. gondii in Khuzestan province as the etiologic agent of ocular toxoplasmosis and physicians should consider diagnostic methods for identifying the infection when they visit the patients. 
Keywords Toxoplasmosis - Toxocariasis - Ocular · ELISA $\cdot$ PCR

\section{Introduction}

Toxoplasmosis is a parasitic infection caused by a protozoan called Toxoplasma gondii [1]. Human infection with toxoplasmosis occurs in both acquired and congenital forms. T. gondii is known to be a major cause of Chorioretinitis. In this case, the ulcers in the retina are associated with central necrosis. Lack of timely detection can cause serious complications in the patient and cause retinal loss [2]. The emergence of clinical symptoms is associated with the positive development of anti-T. gondii antibodies, which is important in basic diagnosis. Currently, the diagnosis of ocular toxoplasmosis is based on the observation of necrotic lesions in the fundus and response to treatment. Nevertheless, due to the non-obvious and non-typical cases, and the concealment of the fundus in some cases, the diagnosis is problematic. Therefore, by locating antibodies in the serum of patients and identifying the parasite in the blood of patients with ocular lesions, timely detection of ocular toxoplasmosis can be made. Although the acute phase of infection in healthy people is often asymptomatic, but toxoplasmic Chorioretinitis may be associated with diminished vision, blindness and glaucoma, and this is more likely to occur when the optic nerve or maculae is involved [3, 4].

Often toxoplasmic Chorioretinitis is caused in the USA and Europe as a result of congenital infections. In this area, most patients do not show symptoms, and the highest incidence of symptoms occurs in the second and third decades of life [5]. However, several other studies have shown that Chorioretinitis can occur in acquired acute toxoplasmosis [6-12].

The specific pathologic findings along with the positive serology of anti-T. gondii antibodies, can be very important in the detection of contamination. Clinical symptoms are in many cases non-specific and make diagnosis difficult [13]. Therefore, erroneous and non-specific treatment not only does not prevent further damage to the eye, but also non-patient subjects are exposed to toxic side effects of unnecessary drugs [14]. Among the laboratory diagnostic methods for ocular toxoplasmosis, cellular culturing of aqueous and vitreous humors and finding localized antibodies in eye fluids are reported as helpful methods. However due to the low amount of sample, low sensitivity and invasive approaches, are not recommended. Finding localized antibodies in eye fluids may also be helpful, but this procedure is also invasive and may damage the eye.

Blood sampling and the study of anti-T. gondii antibodies, as well as parasite tracing in these samples can be very helpful with regard to its simple and noninvasive nature.

Many serologic cases have been able to detect antiT.gondii $\operatorname{IgM}$ and $\operatorname{IgG}$ antibodies in the serum of patients [15]. Of these, ELISA has a high sensitivity and specificity [16]. IgG avidity test is used to differentiation patients with acute infection from those with chronic infection. In this method, sera in chronic phase of infection shows high avidity index and sera in acute phase of infection shows low avidity index [17].

By using PCR, $T$. gondii parasite has been identified in many clinical specimens, including amniotic fluid [18], cerebrospinal fluid [19], and human blood [20].

Toxocariasis is a worm disease of zoonosis and is caused in humans by the presence of Toxocara canis and Toxocara cati larvae that cannot be mature in humans [21]. T. canis in the intestines of dogs and T. cati is in the cat's intestine and these animals are considered as the final hosts of parasites. One of the most important forms of human toxocariasis is ocular larva migrants (OLM), in which larvae migrates to eye and make endophthalmos chronic granuloma or inflammation of the retina and inflammation of the iris [22]. These granulomas can cause retinal degeneration or retinal detachment, and in this case, blindness is common. Dangerous conditions are when the mark is mistaken for retinoblastoma and causes eye drainage [23].

Therefore, this study aims to investigate ocular toxoplasmosis by ELISA, IgG avidity, and molecular PCR methods, and to investigate ocular toxocariasis in patients with ophthalmic disorders using the ELISA serology method.

\section{Methods:}

\section{Ethics statement}

This study was approved by the Ethics Committee of Ahvaz Jundishapur University of Medical Sciences (ethics code: IR.AJUMS.REC.1394.359). 
Ocular toxoplasmosis detection

\section{Patients and blood samples}

This descriptive cross-sectional study was conducted from October 2017 to April 2019. A total of 310 patients with ocular symptoms, most common presenting visual impairment, who referred to the ophthalmology department of Imam Khomeini Hospital, Ahvaz Jundishapur University of Medical Sciences, Ahvaz Iran, were examined by an ophthalmologist and confirmed by an ocular examination. After completing the consent form, patients were registered and completed the questionnaire. $5 \mathrm{cc}$ of venous blood was prepared from each patient, centrifuges, and serum samples, and buffy coat was prepared and kept in $-20{ }^{\circ} \mathrm{C}$ until used. In order to compare the results, 100 blood samples were collected from healthy subjects, and all tests performed on patients in this group were also performed.

\section{Serology tests}

ELISA Presence of IgM and IgG antibodies in sera were determined by standard ELISA commercial kit (IgG-Nova Lisa, Dietzenbach, Germany) in accordance with the manufacturer's instruction. IgG and IgM positive samples were examined using IgG avidity method with the aim of identifying the acute and chronic infections. The interpreted results for the test was that avidity of $>40 \%$ suggest chronic infection and of $<40 \%$ suggest acute infection, based on the directions of NovaLisa ${ }^{\circledR}$ Toxoplasma gondii IgG Avidity Test (Toxo-IgG avidity kit; NOVA TEC-GmbH) through the ELISA system.

\section{Molecular tests}

Nested PCR All serology positive specimens were evaluated by Nested PCR with the aim of detecting B1 T. gondii DNA in buffy coats. Nested PCR was performed using two specific primer pairs of the B1 gene including B1-nested PCR1:5'TCAAGCAGCGTATTGTCGAG-3' and B1-nested PCR1: 5'-CCGCAGCGACTTCTATCTCT- ${ }^{\prime}$ for the first round and B1-nested PCR2: $5^{\prime}$ GGAACTGCATCCGTTCATGAG-3' and B1-nested PCR2: 5'-TCTTTAAAGCGTTCGTGGTC-3' for the second round, and the $194 \mathrm{bp}$ fragment was amplified
$[24,25]$. PCR products were loaded on a $2 \%(\mathrm{w} / \mathrm{v})$ agarose gel and visualized by staining with DNA Safe Stain.

\section{Ocular toxocariasis detection}

Serology test To determine the rate of toxocariasis among patients, anti-toxocara $\mathrm{IgG}$ antibody was evaluated in sera by ELISA method. Toxocara ELISA kit (Bordier Affinity Products, Crissier, Switzerland) was used for this purpose [26].

Data analysis

Statistical analysis of the data was performed using Chi-square test. Values of $P<0.05$ were considered statistically significant.

\section{Result:}

Toxoplasmosis detection

In this study, 310 patients were diagnosed with ocular toxoplasmosis, including 204 women and 106 men. In total, 130 out of 310 patients $(41.93 \%)$ were positive by ELISA, of them 121 (39\%) IgG positive and nine (2.9\%) IgM positive were diagnosed.

In the group of female, $76(37.25 \%)$ patients had $\mathrm{IgG}$ and one $(0.49 \%)$ had $\operatorname{IgM}$, and in the male group $45(42.45 \%)$ had $\operatorname{IgG}$ and eight (7.54\%) had IgM, respectively. For IgG antibody, there was no significant difference between men and women $(P>0.05)$, but for IgM, this difference was significant $(P<0.05)$.

Ocular toxoplasmosis was seen in different age groups with the highest incidence of IgG anti body over the age of 50 years, with 56 out of 120 (46.7\%) and $\operatorname{IgM}$ positive for six (5\%), both of which differences were significant $(P<0.05)$ (Table 1).

Of 121 patients with $\mathrm{IgG}^{+}, 119(98.35 \%)$ were diagnosed with high IgG avidity as chronic and two $(1.65 \%)$ equivocal were diagnosed.

By PCR molecular method, the $194 \mathrm{bp}$ fragment was amplified [24, 25]. Eleven out of 310 patients (3.54\%) had T. gondii DNA in the blood, with the highest number in the age group $>50$ years old with five patients (4.17\%) (Table 1 and Fig. 1). 
Table 1 Prevalence of toxoplasmosis in patients with ocular lesions according to gender and age variables

\begin{tabular}{llll}
\hline Variables & $\operatorname{IgG}+$ & $\operatorname{IgM}+$ & $\mathrm{PCR}+$ \\
\hline Gender & & & \\
Female & $76 / 204(37.25 \%)$ & $1 / 204(0.49 \%)$ & $2 / 204(0.98 \%)$ \\
Male & $45 / 106(42.45 \%)$ & $8 / 106(7.54 \%)$ & $9 / 106(4.71 \%)$ \\
Significant & $P>0.05$ & $P<0.05$ & $P<0.05$ \\
Age (years) & & & \\
$<10$ & 0 & 0 & 0 \\
$10-20$ & 0 & 0 & 0 \\
$21-30$ & $9 / 29(31.03 \%)$ & $3 / 29(10.34 \%)$ & $1 / 29(3.44 \%)$ \\
$31-40$ & $18 / 62(29.03 \%)$ & $0 / 62(0)$ & $3 / 62(4.83 \%)$ \\
$41-50$ & $38 / 83(45.78 \%)$ & $0 / 83(0)$ & $2 / 83(2.40 \%)$ \\
$>50$ & $65 / 120(54.17 \%)$ & $6 / 120(5 \%)$ & $5 / 120(4.17 \%)$ \\
Significant & $P<0.05$ & $P<0.05$ & $P<0.05$ \\
\hline
\end{tabular}

antibodies in women was $2 / 60(3.33 \%)$ and in men was $1 / 40(2.5 \%)$. IgG avidity test showed that $12 / 20$ $(60 \%)$ of $\mathrm{IgG}$ positive samples were diagnosed as chronic infection.

The results of the PCR molecular assay were $T$. gondii DNA not found in the women group, but in the men group, it was $2 / 40(5 \%)$ (Table 2).

\section{Discussion}

Ocular toxoplasmosis is a progressive and recurrent disease; with new lesions on the margins of the old scars and various parts of the eye, these lesions further affect the retina, which is the most common cause of retinal and posterior uveitis, with symptoms such as blurred vision, cataracts, glaucoma, flutter, opacity in the lens, and retinal vascular hyperemia [27, 28]. In this study, all patients who had been diagnosed with ocular lesions by an ophthalmologist were tested in a laboratory that has a supportive role. In this study, the prevalence of anti-Toxoplasma antibodies in patients

Table 2 Prevalence of toxoplasmosis in health people according to gender variable

\begin{tabular}{llll}
\hline Variables & $\operatorname{IgG}+$ & $\operatorname{IgM}+$ & $\mathrm{PCR}+$ \\
\hline Gender & & & \\
Female & $13 / 60(21.67 \%)$ & $2 / 60(3.33 \%)$ & $0 / 60(0 \%)$ \\
Male & $7 / 40(17.50 \%)$ & $1 / 40(2.5 \%)$ & $2 / 40(5 \%)$ \\
Significant & $P>0.05$ & $P>0.05$ & $P<0.05$ \\
\hline
\end{tabular}


with ocular inflammation was $41.93 \%$, while in the control group, it was $20 \%$, which showed a significant difference $(P<0.05)$.

In the present study, it was found that the prevalence of toxoplasmosis increases with age. The frequency of $\operatorname{IgG}$ and IgM antibodies were significantly different in different age groups $(P=0.03)$; with increasing age, these rates increased. In this study, the age group of 50 years and above, both IgM $(5 \%)$ and $\operatorname{IgG}(54.17 \%)$ were more frequent than the rest of the age group. These findings are consistent with those published by other studies [10, 29, 30].

Glasner et al. reported the prevalence of ocular toxoplasmosis was $21.3 \%$ in persons of age 13 years or older and was $0.9 \%$ in 1-8-year-old children [30].

In this study, the frequency of $\operatorname{IgG}$ and $\operatorname{IgM}$ antibodies in males and females was not significantly different $(P>0.05)$, while other studies reported a different incidence in male and female genders. Suresh et al. (2012) in Brazil showed higher prevalence of anti-toxoplasma antibodies in women than men [31]. With the IgG avidity method, the results showed that $98.35 \%$ of the samples had high avidity, indicating that ocular toxoplasmosis caused by reactivation of chronic infection of toxoplasma. This is similar to the results by Rahimi-Esboei et al. who reported that $87.2 \%$ of the cases had high IgG avidity in IranTeheran in their prospective study on patients with ocular toxoplasmosis (OT) who referred to the Farabi Eye Hospital, Tehran, Iran [32]. Also our result consistent with the results by Jones et al. [33] who showed that $11.7 \%$ of their cases in the USA have recently acquired infection and $88.3 \%$ were $\mathrm{IgG}$ positive/IgM negative, which indicated they had chronic ocular toxoplasmosis. Although the diagnosis of new acquired acute toxoplasmosis cannot be founded on low IgG avidity, but primary toxoplasmosis progressed during the recent 5 months is rejected by a high IgG avidity index [34]. IgG avidity can help to differentiate between reactivation of old infection and recent infection. In our study, in the OT group, PCR was positive for 11 samples but in the control group, two samples were positive by the method $(P<0.05)$. In other studies, the molecular method indicated that the DNA of $T$. gondii was detected in the blood of the subjects with ocular toxoplasmosis. Bou et al. In 1999, in order to evaluate the PCR method for the diagnosis of ocular toxoplasmosis, 56 blood samples and 56 samples of aqueous humor were studied in healthy individuals (with a strong immune system) but had eye lesions. Of these, 15 subjects with clinical symptoms of ocular toxoplasmosis showed an increase in IgG antibody titers but not IgM antibodies. In this study, using PCR method, it was shown that in samples of aqueous samples positive for PCR, their blood samples also were positive. This study has shown that ocular toxoplasmosis should not be considered as a local effect, but Toxoplasma can be present at the same time in the blood. Also, this research has determined that PCR can separate toxoplasmic ocular lesions from nontoxoplasmic lesions [28].

In our study, of the 130 positive cases with ELISA, only 11 cases were positive by PCR method. These results are consistent with the study by Bourdin et al. 2014 who tested two different DNA extraction protocols, using either $2 \mathrm{ml}$ (large volume) or $200 \mu \mathrm{l}$ (small volume) of whole blood and reported sensitivity was poor, i.e., $25 \%$ and $4.1 \%$ for the large and small volume extractions, respectively [35].

Ocular toxoplasmosis is usually caused by the reactivation of toxoplasma tissue cysts, which is seen in the chronic state of infection. In current study, the results of the IgG avidity method showed the same; Of 121 OT with $\operatorname{IgG}+, 119$ (98.35\%) were diagnosed with high $\mathrm{IgG}$ avidity indicating of chronic phase of the infection.

In conclusion, considering the significant difference between the results of serological and molecular methods from case and control groups, it can be concluded that $T$. gondii in Khuzestan province is the causative agents of ocular problems and physicians should consider diagnostic methods for identifying the infection when they visit the patients.

Acknowledgements The authors thank the ophthalmology and laboratory departments of Imam Khomeini Hospital in Ahvaz for their valuable contributions.

Funding This study was funded by Ahvaz Jundishapur University of Medical Sciences (OG-94115).

\section{Compliance with ethical standards}

Ethical approval All procedures performed in studies involving human participants were in accordance with the ethical standards of the institutional and/or national research committee and with the 1964 Helsinki declaration and its later amendments or comparable ethical standards. 
Informed consent Informed consent was obtained from all individual participants included in the study.

Open Access This article is licensed under a Creative Commons Attribution 4.0 International License, which permits use, sharing, adaptation, distribution and reproduction in any medium or format, as long as you give appropriate credit to the original author(s) and the source, provide a link to the Creative Commons licence, and indicate if changes were made. The images or other third party material in this article are included in the article's Creative Commons licence, unless indicated otherwise in a credit line to the material. If material is not included in the article's Creative Commons licence and your intended use is not permitted by statutory regulation or exceeds the permitted use, you will need to obtain permission directly from the copyright holder. To view a copy of this licence, visit http://creativecommons.org/licenses/by/4.0/.

\section{References:s}

1. Chen XG (2009) Toxoplasma gondii: past, present and future. Zhongguo Ji Sheng Chong Xue Yu Ji Sheng Chong Bing Za Zhi 5:426-431

2. Bou G, Figueroa MS, Martí-Belda P, Navas E, Guerrero A (1999) Value of PCR for Detection of Toxoplasma gondii in aqueous humor and blood samples from immunocompetent patients with ocular toxoplasmosis. J Clin Microbiol 11:3465-3468

3. Holland GN, O'Connor GR, Belfort R Jr, Remington JS (1996) Toxoplasmosis. In: Pepose JS, Holland GN, Wilhelmus KR (eds) Ocular infection and immunity, vol 1, 1st edn. St, Mosby Yearbook, Louis, pp 183-223

4. Khademvatan S, Saki J, Khajeddin N, Izadi-Mazidi M, Beladi R, Shafiee B, Salehi Z (2014) Toxoplasma gondii exposure and the risk of schizophrenia. Jundishapur $\mathbf{J}$ Microbiol 7(11):e12776

5. Montoya JG, Remington JS (1996) Toxoplasmic chorioretinitis in the setting of acute acquired toxoplasmosis. Clin Infect Dis 23(2):277-282

6. Akstein RB, Wilson LA, Teutsch SM (1982) Acquired toxoplasmosis. Ophthalmology 89(12):1299-1302

7. Masur H, Jones TC, Lempert JA, Cherubini TD (1978) Outbreak of toxoplasmosis in a family and documentation of acquired retinochoroiditis. Am J Med 64(3):396-402

8. Saari M, Vuorre I, Neiminen H, Räisänen S (1976) Acquired toxoplasmic chorioretinitis. JAMA. Ophthalmology 94(9):1485-1488. https://doi.org/10.1001/archopht.1976. 03910040319005

9. Kayhoe DE, Jacobs L, Beye HK, McCullough NB (1957) Acquired toxoplasmosis: observations on two parasitologically proved cases treated with pyrimethamine and triple sulfonamides. N Engl J Med 257(26):1247-1254

10. Elmore SA, Jones JL, Conrad PA, Patton S, Lindsay DS, Dubey J (2010) Toxoplasma gondii: epidemiology, feline clinical aspects, and prevention. Trends Parasitol 26(4):190-196

11. Robinson P (1947) A case of toxoplamosis; with recovery. Ann Paediatr 168(3):134-137
12. Luft B, Conley F, Remington J, Laverdiere M, Levine J, Strandberg D, Wagner K, Craven P, File T, Rice N (1983) Outbreak of central-nervous-system toxoplasmosis in western Europe and North America. The Lancet 321(8328):781-784

13. Khademvatan S, Riahi F, Izadi-Mazidi M, Khajeddin N, Yousefi E (2018) Toxoplasma gondii exposure and the risk of attention deficit hyperactivity disorder in children and adolescents. Pediatr Infect Dis J 37(11):1097-1100

14. Khademvatan S, Khajeddin N, Izadi S, Yousefi E (2014) Investigation of anti-Toxocara and anti-Toxoplasma antibodies in patients with schizophrenia disorder. Schizophr Res Treatment 2014:230349. https://doi.org/10.1155/2014/ 230349

15. Gharavi M, Jalali S, Khademvatan S, Heydari S (2011) Detection of IgM and IgG anti-Toxoplasma antibodies in renal transplant recipients using ELFA, ELISA and ISAGA methods: comparison of pre-and post-transplantation status. Ann Trop Med Parasitol 105(5):367-371

16. Fuccillo D, Madden D, Tzan N, Sever J (1987) Difficulties associated with serological diagnosis of Toxoplasma gondii infections. Diagn Clin Immunol 5(1):8-13

17. Horváth KN, Szénási Z, Danka J, Kucsera I (2005) Value of the IgG avidity in the diagnosis of recent toxoplasmosis: a comparative study of four commercially available antiToxoplasma gondii IgG avidity assays. Acta Parasitol 50(3):255-260

18. Jenum P, Holberg-Petersen M, Melby K, Stray-Pedersen B (1998) Diagnosis of congenital Toxoplasma gondii infection by polymerase chain reaction (PCR) on amniotic fluid samples: the Norwegian experience. Apmis 106(7-12):680-686

19. Cingolani A, De Luca A, Ammassari A, Murri R, Linzalone A, Grillo R, Antinori A (1996) PCR detection of Toxoplasma gondii DNA in CSF for the differential diagnosis of AIDS-related focal brain lesions. J Med Microbiol 45(6):472-476

20. Kompalic-Cristo A, Frotta C, Suárez-Mutis M, Fernandes O, Britto C (2007) Evaluation of a real-time PCR assay based on the repetitive $\mathrm{B} 1$ gene for the detection of Toxoplasma gondii in human peripheral blood. Parasitol Res 101(3):619-625

21. Miyazaki III I (1991) Section III. Nematode zoonoses. 33. Gnathostomiasis. An illustrated book of helminthic zoonoses. International Medical Foundation of Japan, Tokyo, Japan, 368409

22. Stewart JM, Cubillan LD, Emmett T, Cunningham J (2005) Prevalence, clinical features, and causes of vision loss among patients with ocular toxocariasis. Retina 25(8):1005-1013

23. Chuah C, Lim M, Seah L, Ling Y, Chee S (2006) Pseudoretinoblastoma in enucleated eyes of Asian patients. Singapore Med J 47(7):617

24. Burg JL, Grover CM, Pouletty P, Boothroyd J (1989) Direct and sensitive detection of a pathogenic protozoan, Toxoplasma gondii, by polymerase chain reaction. J Clin Microbiol 27(8):1787-1792

25. Mousavi M, Saravani R, Modrek MJ, Shahrakipour M, Sekandarpour S (2016) Detection of Toxoplasma gondii in diabetic patients using the nested PCR assay via RE and B1 genes. Jundishapur J Microbiol 9(2):e29493 
26. Kwon N-H, Oh M-J, Lee S-P, Lee B-J, Choi D-C (2006) The prevalence and diagnostic value of toxocariasis in unknown eosinophilia. Ann Hematol 85(4):233-238

27. Dubey JP, Jones JL (2008) Toxoplasma gondii infection in humans and animals in the United States. Int $\mathbf{J}$ Parasitol 38(11):1257-1278. https://doi.org/10.1016/j.ijpara.2008. 03.007

28. Bou G, Figueroa MS, Martí-Belda P, Navas E, Guerrero A (1999) Value of PCR for detection of Toxoplasma gondii in aqueous humor and blood samples from immunocompetent patients with ocular toxoplasmosis. J Clin Microbiol 37(11):3465-3468

29. Dubey J (2009) History of the discovery of the life cycle of Toxoplasma gondii. Int J Parasitol 39(8):877-882

30. Glasner PD, Silveira C, Kruszon-Moran D, Martins MC, Burnier M Jr, Silveira S, Camargo ME, Nussenblatt RB, Kaslow RA, Belfort R Jr (1992) An unusually high prevalence of ocular toxoplasmosis in southern Brazil. Am J Ophthalmol 114(2):136-144

31. Suresh S, Nor-Masniwati S, Nor-Idahriani MN, Wan-Hazabbah W-H, Zeehaida M, Zunaina E (2012) Serological IgG avidity test for ocular toxoplasmosis. Clinical Ophthalmology (Auckland, NZ) 6:147
32. Rahimi-Esboei B, Zarei M, Mohebali M, Valian HK, Shojaee S, Mahmoudzadeh R, Salabati M (2018) Serologic tests of IgG and IgM antibodies and IgG avidity for diagnosis of ocular toxoplasmosis. Korean J Parasitol 56(2):147

33. Jones JL, Kruszon-Moran D, Sanders-Lewis K, Wilson M (2007) Toxoplasma gondii infection in the United States, 1999-2004, decline from the prior decade. Am J Trop Med Hygiene 77(3):405-410

34. Paul M (1999) Immunoglobulin G avidity in diagnosis of toxoplasmic lymphadenopathy and ocular toxoplasmosis. Clin Diagn Lab Immunol 6(4):514-518

35. Bourdin C, Busse A, Kouamou E, Touafek F, Bodaghi B, Le Hoang P, Mazier D, Paris L, Fekkar A (2014) PCR-based detection of Toxoplasma gondii DNA in blood and ocular samples for diagnosis of ocular toxoplasmosis. J Clin Microbiol 52(11):3987-3991

Publisher's Note Springer Nature remains neutral with regard to jurisdictional claims in published maps and institutional affiliations. 